\title{
FATIGUE BEHAVIOR OF BUTT WELDED JOINTS CONTAINING INCLINED LACK-OF-PENETRATION
}

\author{
In-Tae KIM ${ }^{1}$, Kentaro YAMADA ${ }^{2}$ and Shigenobu KAINUMA ${ }^{3}$ \\ ${ }^{1}$ Member of JSCE, M. Eng., Graduate Student, Dept. of Civil Eng., Nagoya University \\ (Furo-cho, Chikusa-ku, Nagoya 464-8603, Japan) \\ ${ }^{2}$ Member of JSCE, Ph. D., Professor, Dept. of Civil Eng., Nagoya University \\ (Furo-cho, Chikusa-ku, Nagoya 464-8603, Japan) \\ ${ }^{3}$ Member of JSCE, Dr. Eng., Assistant Professor, Dept. of Civil Eng., Nagoya University \\ (Furo-cho, Chikusa-ku, Nagoya 464-8603. Japan)
}

\begin{abstract}
In order to study fatigue behavior of welded joints including weld defects with certain angles to the applied stress, butt welded specimens containing lack-of-penetration inclined at angles of 0,15 and 30 degrees to the direction perpendicular to the applied stress were fatigue-tested. The observations of fracture surfaces indicate that the fatigue crack propagates on the same plane as the inclined lack-of-penetration until it appears at the surfaces of the specimen, and then the through-thickness crack tends to propagate perpendicularly to the applied stress. The comparison of test results indicates that change in the fatigue life is little, despite the different inclined angles of 0,15 and 30 degrees.
\end{abstract}

Key Words : fatigue, butt welds, lack-of-penetration, inclined angle

\section{INTRODUCTION}

In most welded steel structural components, the weld defects, such as blowholes, slag inclusion, lack-of-penetration and similar imperfections, are not avoidable due to economic and technical reasons. The defects detected by non-destructive inspection raise engineering problems whether or not such defects are to be accepted in order to maintain structural integrity subjected to cyclic loading. If the defects are not repaired or if the repair is improper, fatigue cracks are initiated at the defects and propagate in the early stage. Thus, reasonable acceptance-criteria are needed to assess the severity of actual defects in welded joints.

In order to determine the acceptance criteria, researchers have investigated the factors affecting fatigue strength of welded joints, such as defect-size, defect-type, defect-location and/or welding residual stresses ${ }^{1)-6)}$. For example, Miki et al. ${ }^{1)}$ recently tested thick butt welded specimens with five defect-types, such as lack-of-fusion, blowholes, cracks, incomplete penetration and slag inclusion. The authors showed that welded joints containing defects of certain size still satisfy the current design S-N curve which basically derived from the specimens with no detectable defects.

In actual welded structures, shape, size, location and direction of weld defects show rather wide variation. For example, a crack or crack-like-defect exists and is not perpendicular to applied stress direction. For such defects, Fatigue Design Rules ${ }^{7,8)}$ often recommend that the initial crack size evaluated by projecting the defect on a plane perpendicular to the applied stress direction be used for estimating fatigue strength of the joints. However, fatigue behavior of such defects is not clearly defined. It may be that the fatigue strength of welded joints with defects is the lowest when the defects are placed perpendicularly to the stress.

In this study, fatigue tests were carried out on butt welded specimens containing lack-of-penetration (LOP) at the center of a tensile plate. The LOPs were intentionally inclined at 0,15 and 30 degrees to the direction perpendicular to the applied stress. Uniaxial tensile cyclic loading was applied to 
introduce local combined normal and shear stresses to the inclined LOP. The effect of the inclined angles on fatigue crack propagation behavior and fatigue life is discussed.

\section{FATIGUE TEST}

\section{(1) Fatigue Test Program}

Fatigue test specimens are shown in Fig.1. The specimens are made of $9 \mathrm{~mm}$ thick steel plate conformed to JIS SM490A. The chemical composition and mechanical properties of the steel plates are listed in Table 1. The specimens of $200 \mathrm{~mm}$ wide and $1000 \mathrm{~mm}$ long were butt-welded at the center, which contains lack-of-penetration(LOP) inclined at 0,15 and 30 degrees to the width direction of the specimens. The specimens with inclined angles of $\alpha=0,15$ and 30 degrees were named as B0S, B15S and B30S, respectively. The weld reinforcements of the specimens were removed by a grinder so that fatigue cracks would be initiated at the LOP. The number of B0S, B15S and B30S is eight, ten and eleven respectively. Four specimens were tested with weld reinforcements, which were named as B0G. The weld toes were ground by a disk grinder. In order to observe crack propagation, a few beach-mark loading tests were carried out. In the beach mark tests the stress range was halved, while the maximum stress was kept the same.

The butt-welding was carried out as follows. Double beveled grooves were made at the plates, except LOP was to be introduced. Two plates were first tack-welded, and then semi-automatically butt-welded in double beveled part. Finally, whole welding was placed from one end to the other. In this way, the LOPs of about $30 \mathrm{~mm}$ long and $3 \mathrm{~mm}$ deep were intentionally placed. Macro-sections with and without LOP are shown in Fig.2. Under $0.1 \mathrm{~mm}$ gap size of LOP was measured through cutting some pre-test specimens made under the same welding condition as the test specimens.

\section{(2) Testing Procedure}

Tensile fatigue tests with constant amplitude stress cycles were carried out by an Amsler type fatigue-testing machine with $980 \mathrm{kN}$ loading capacity at $4.5 \mathrm{~Hz}$. Three stress ranges were mainly applied and the minimum stress was fixed at $16.3 \mathrm{MPa}$. For $117 \mathrm{MPa}$ stress ranges, the minimum stress was fixed at $16.3 \mathrm{MPa}$ or the maximum stress was fixed at $221 \mathrm{MPa}$. Thus, the stress ratios of the minimum stress to the maximum stress, $\mathrm{R}$, are 0.12 and 0.47 respectively. Most fatigue tests of the

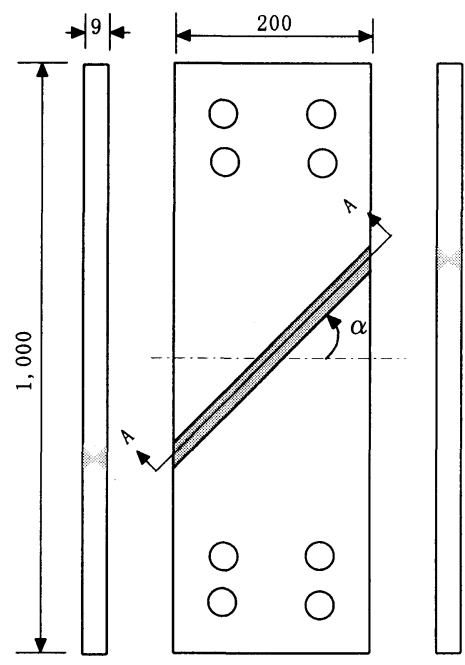

Section $A-A$

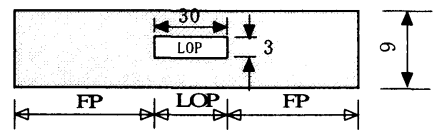

Butt-welding and grinding

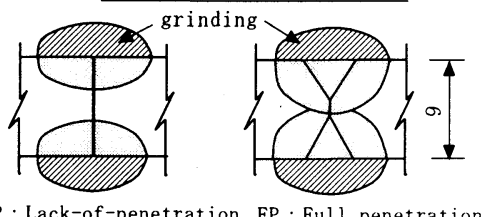

(dimensions in $\mathrm{mm}$ )

Fig. 1 Fatigue test specimens

Table 1 Chemical composition and mechanical properties of base metal(after mill sheet)

\begin{tabular}{|c|c|c|c|c|}
\hline $\mathrm{C}(\%)$ & $\mathrm{Si}(\%)$ & $\mathrm{Mn}(\%)$ & $\mathrm{P}(\%)$ & $\mathrm{S}(\%)$ \\
\hline 0.11 & 0.43 & 1.16 & 0.018 & 0.013 \\
\hline
\end{tabular}

\begin{tabular}{|c|c|c|}
\hline Yield point & Tensile Strength & Elongation \\
\hline $426 \mathrm{MPa}$ & $524 \mathrm{MPa}$ & $24 \%$ \\
\hline
\end{tabular}

specimens with $\mathrm{R}=0.47$ were carried to check effect of compressive residual stress near the LOP after the fatigue tests of some other specimens with $\mathrm{R}=0.12$. Six strain gages were attached to all specimens to calibrate the applied load statically and dynamically, and to avoid any eccentricity. Shielded copper wires of $0.04 \mathrm{~mm}$ diameter were glued at the center of the specimens and at two positions $50 \mathrm{~mm}$ away from the sides of the specimens, as shown in Fig.3. The wires were used as crack detectors. When a fatigue crack cut the wire, the fatigue testing machine was automatically stopped. 


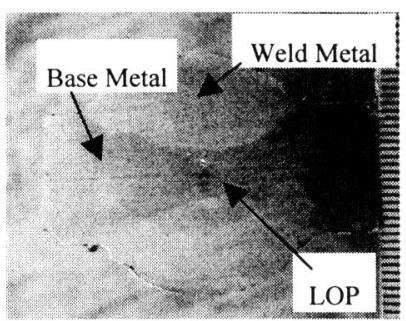

(a) Lack-of-penetration

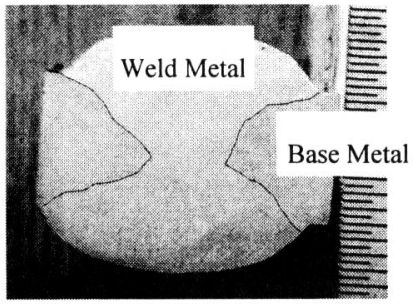

(b) Full penetration

Fig.2 Macro-section

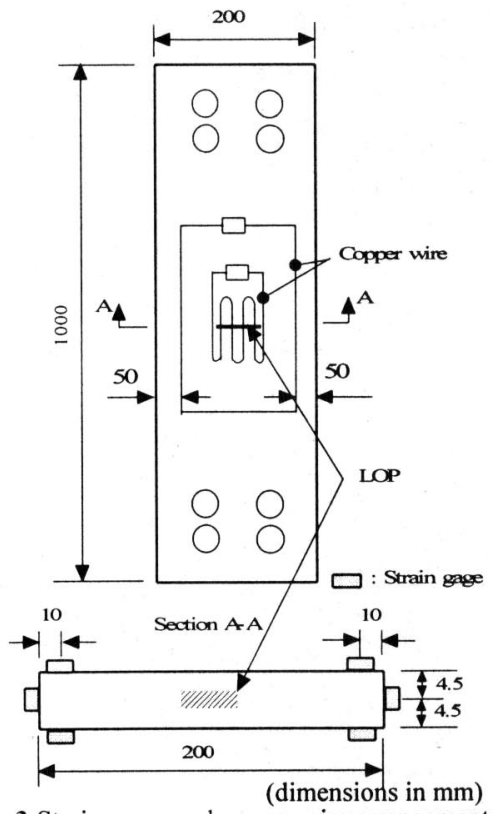

Fig.3 Strain gages and copper wire arrangement

A fatigue tests were carried out until an internal crack appeared at the surfaces of the specimens. The number of cycles needed to propagate the crack from the edge of the LOP to the specimen surface was defined as $\mathrm{N}_{1}$. Then, the test was continued until the through-thickness crack propagated to cut the wires glued at $50 \mathrm{~mm}$ away from the sides of the specimens. This was defined as the final failure of the specimens. The number of cycles needed to propagate the crack from the through-thickness crack to the final failure was defined as $\mathrm{N}_{2}$.

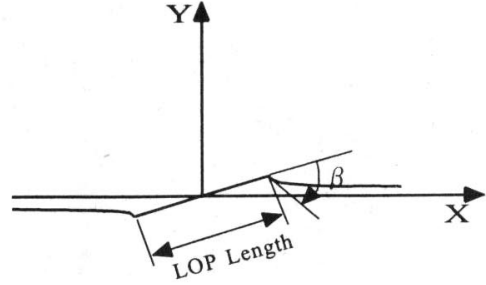

(a) Typical fatigue crack propagation pattern

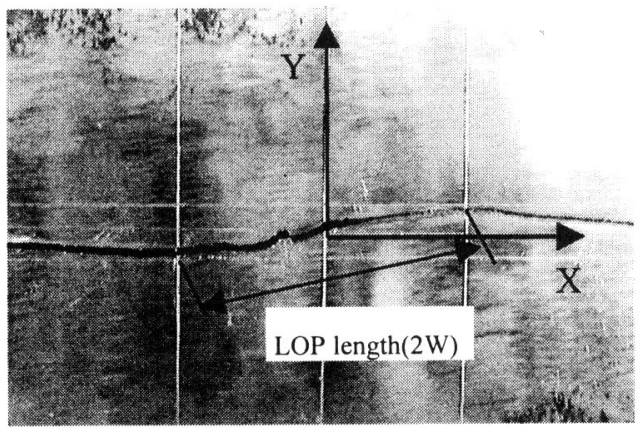

(b) $\mathrm{B} 15 \mathrm{~S}-1$

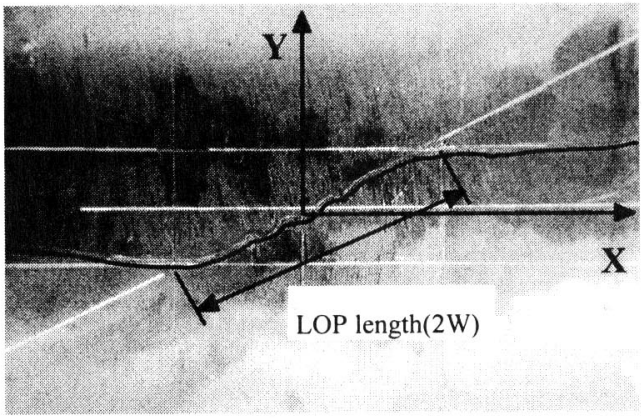

(c) B30S-8

Fig.4 Fatigue crack propagation pattern appeared on the surface

\section{FATIGUE CRACK INITIATION AND PROPAGATION}

\section{(1) General Observation of Fatigue Cracks}

Fatigue cracks originated from the edge of the lack-of-penetration(LOP), and propagated toward the thickness direction of the specimens. Once the crack appeared at the surfaces of the specimen, the through-thickness crack propagated toward the width direction of the specimen. For the B0S specimens, the LOP was placed perpendicularly to the applied stress, and therefore the fatigue crack propagated also perpendicularly to the applied stress.

Typical fatigue crack propagation patterns of B15S and B30S specimens are shown in Fig.4. The two axes, $\mathrm{X}$ and $\mathrm{Y}$, in the figure represent the center 


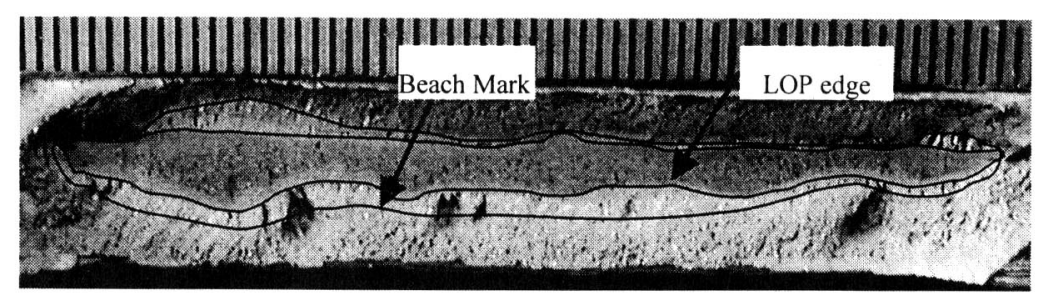

Fig.5 Fracture surface of B0G-3

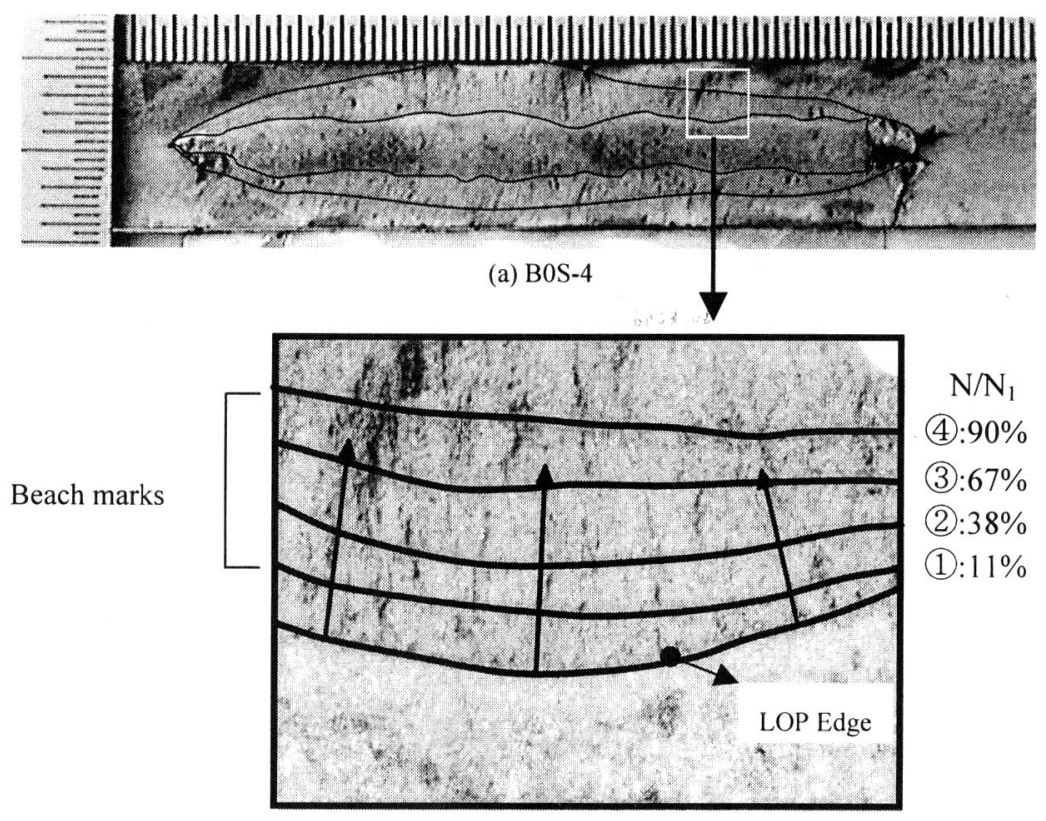

(b) Beach marks in B0S-4

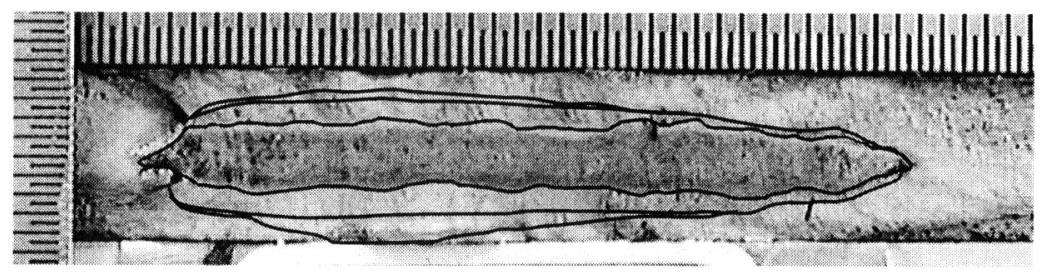

(c) B0S-8

Fig.6 Typical fracture surfaces of B0S specimens( $\alpha=0$ deg.)

line of the specimens perpendicular to the applied stress and the stress direction, respectively. When the crack appeared at the surfaces, it formed a through-thickness crack which had the same inclined angle as the LOP-plane. The crack propagated with the angle $\beta$ in short distance toward the width direction. Then the crack propagated perpendicularly to the applied stress and propagated close to $\mathrm{X}$-axis, as shown in Fig. $\mathbf{4}^{9), 10)}$. The $\beta$ is the angle between the extent line of a through-thickness crack and the crack propagation direction, as shown in Fig.4(a). They were about 30 degrees for $\mathrm{B} 15 \mathrm{~S}$ specimens and about 50 degrees for B30S specimens.

\section{(2) Observation of Fracture Surface}

a) B0G specimens( $\alpha=0$ degree)

In B0G specimens, the weld reinforcements were not removed and the weld toes were ground. Two of the four specimens failed due to fatigue crack initiation from the weld toes, although the LOPs of 2.5 to $3.2 \mathrm{~mm}$ deep existed. For the other two specimens, no fatigue crack from the weld toes was observed after over 1.5 million cycles and the fatigue tests were stopped. However, small fatigue crack 


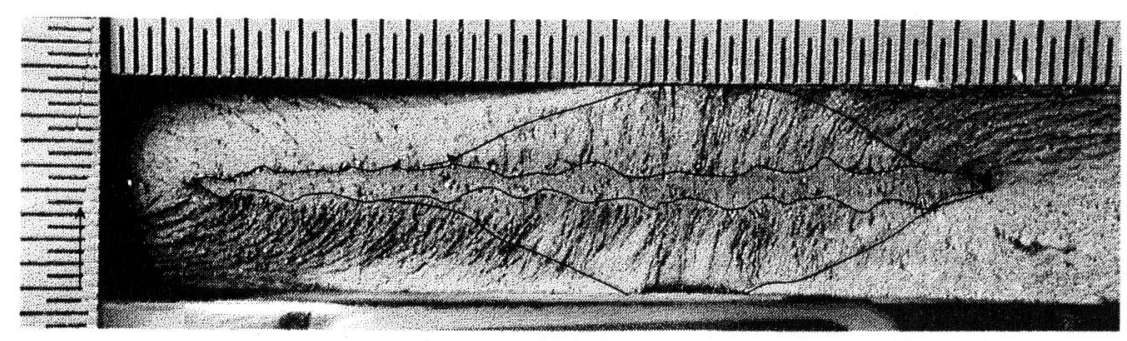

(a) B15S-1

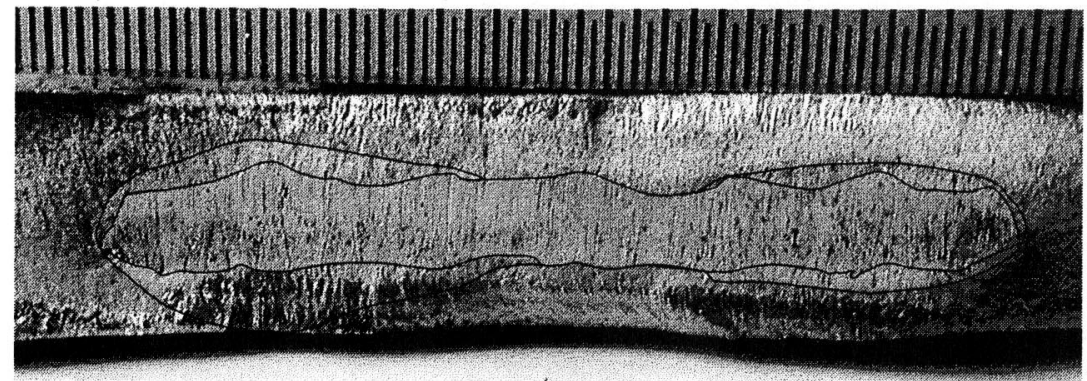

(b) B15S-9

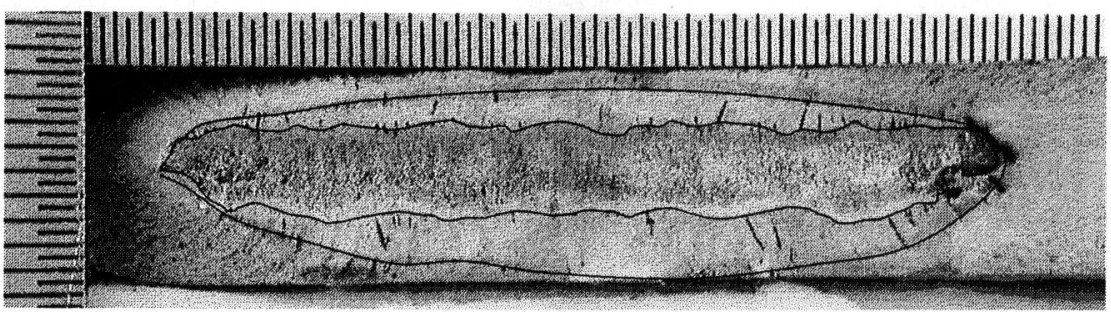

(c) $\mathrm{B} 15 \mathrm{~S}-4$

Fig.7 Typical Fracture Surface of B15S specimens

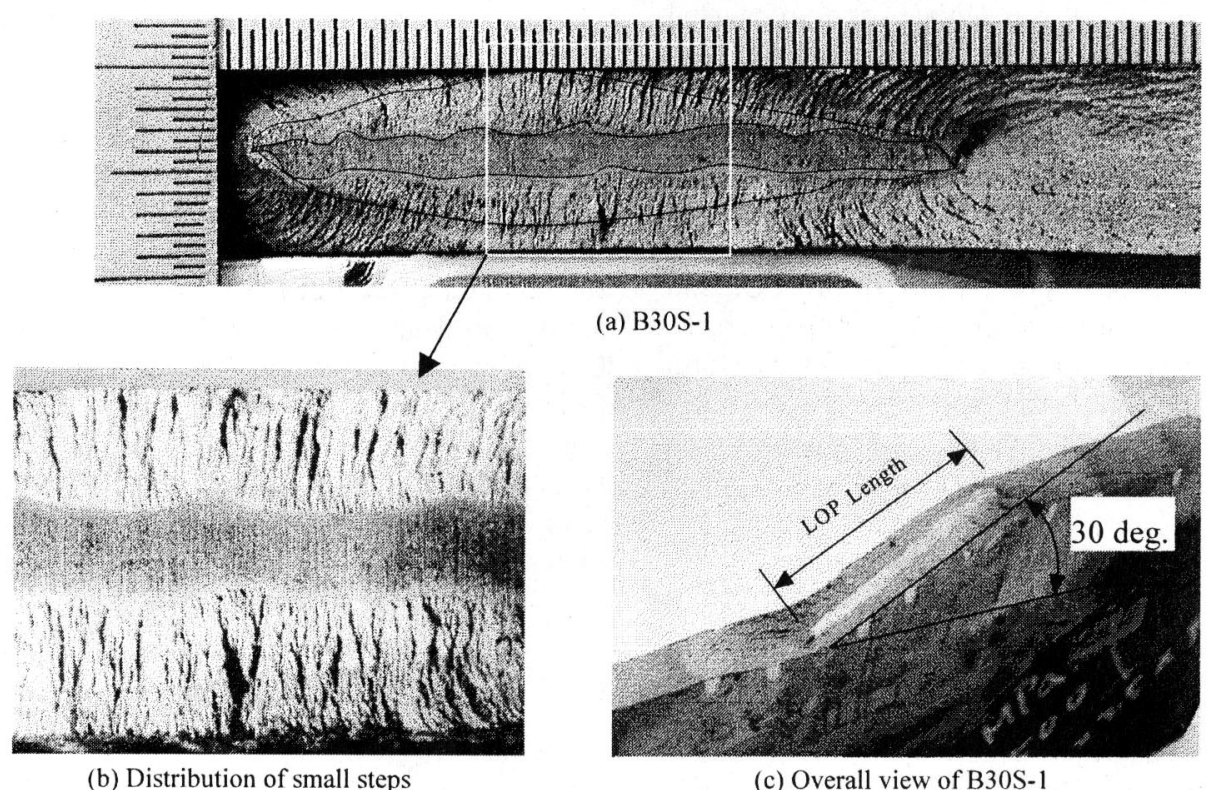

Fig.8 Typical fracture surface of B30S specimens 
initiations were observed at the edge of the LOP on the fracture surfaces. These crack depths were between 0.7 and $1.1 \mathrm{~mm}$. As an example, the fracture surface of B0G-3 specimen is shown in Fig.5.

\section{b) BOS specimens( $\alpha=0$ degree)}

Typical fracture surfaces for B0S specimens are shown in Fig.6. The solid curves in the enlarged figures represent the edges of LOP and beach marks left on the fracture surface. The arrows in the figure represent the direction of fatigue crack propagation. The fatigue crack was initiated along the edge of LOP and propagated toward thickness direction to form a smooth crack front like a curve connecting between convex points of the edge. It eventually propagated to form a narrow elliptical crack. Fatigue crack propagation in concave part of the edge was relatively fast in the early stage of fatigue crack propagation. The simultaneous fatigue crack initiation along the edge seems to be due to high stress concentration along the edge. The fatigue crack propagated mainly toward the thickness direction. No fatigue crack propagation toward the width direction was observed until the crack appeared at the specimen surfaces.

The first beach mark in Fig.6(b) corresponds to 11 percent of $N_{1}$, number of cycles needed to propagate the crack to a through-thickness crack.

c) B15S and B30S specimens( $\alpha=15$ and 30 degree)

When the LOPs were placed with certain angles to the applied stress, two types of fatigue crack initiation and propagation behaviors are observed on the fracture surfaces of B15S and B30S specimens. First, the fatigue crack was initiated and propagated in the same plane as the LOP-plane inclined to the applied stress. Second, multiple fatigue cracks were initiated and propagated along the edge of the LOP perpendicularly to the applied stress.

Typical fracture surfaces of B15S and B30S specimens are shown in Figs.7 and 8. Also drawn curves in the figures represent the edge of LOP and the beach marks. In most specimens, fatigue cracks were simultaneously initiated along the edge to form a narrow elliptical crack, and propagated to the thickness direction. The plane of crack propagation coincides with the LOP-plane inclined to the applied stress.

For B15S-1 and B15S-9 specimens, the fatigue cracks emanated from smaller LOP-sizes, about a half or less in LOP-length, formed one or two elliptical crack and propagated to the thickness direction, as shown in Figs.7(a) and 7(b).

In the previous experiments ${ }^{10), 11), 12)}$, where fatigue crack propagated under combined normal and out-of-plane shear stresses, the fatigue cracks

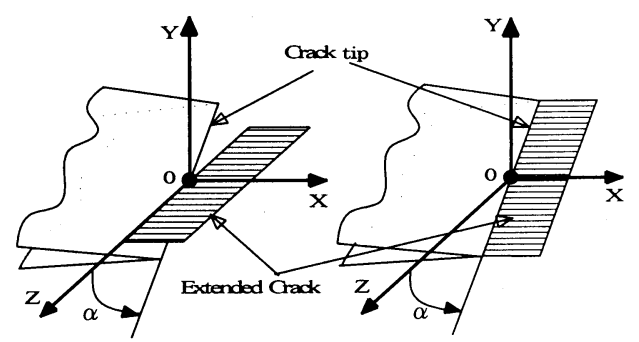

(a) Previous tests

(b) Present tests

Fig.9 Fatigue crack initiation and propagation at crack tip

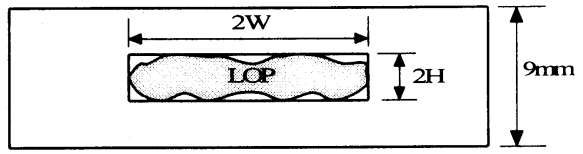

Fig.10 Size and location of defect

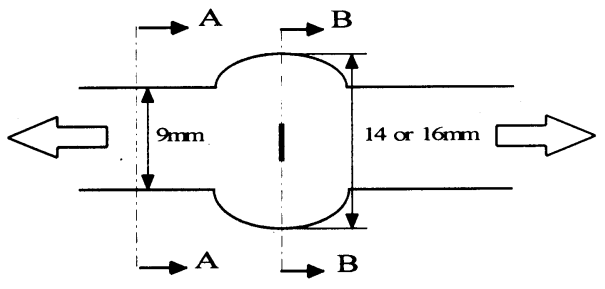

Fig.11 Two section to compute stress ranges

propagated perpendicularly to the maximum principal stress, as shown in Fig.9(a). However, the fatigue cracks of B15S and B30S specimens except B30S-1 propagated on the same plane of inclined LOP until they appeared at the surfaces of the specimens, as shown schematically in Fig.9(b). In the figures, $\mathrm{X}$ and $\mathrm{Y}$ axes represent the direction of the applied stress and the crack propagation, respectively.

Numerous fine facets between small steps were observed on the fracture surfaces of B30S-1 specimen, as shown in Fig.8(b). The fatigue crack was initiated at the same plane as the LOP, which inclined 30 degrees to the section perpendicular to the applied stress, and propagated toward the finite thickness direction. As they propagated, they changed the direction gradually to perpendicular to the applied stress. As a result of this process, the small steps and the fine facets were formed on the fracture surfaces.

\section{FATIGUE LIFE}

\section{(1) General Description}

The fatigue test results are summarized in Table A1. The dimensions of the LOPs in the specimens 


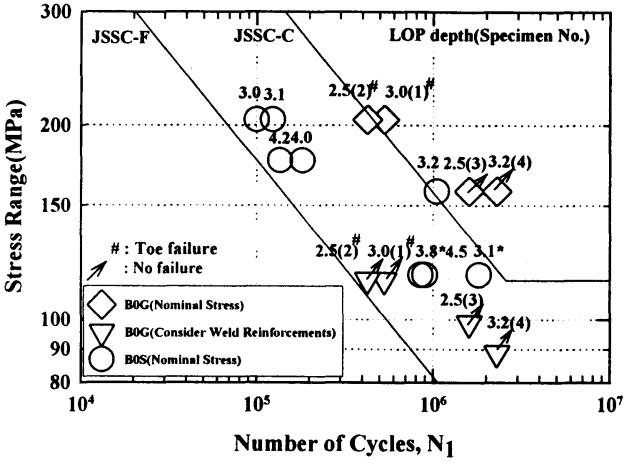

Fig.12 Test results of B0G specimens

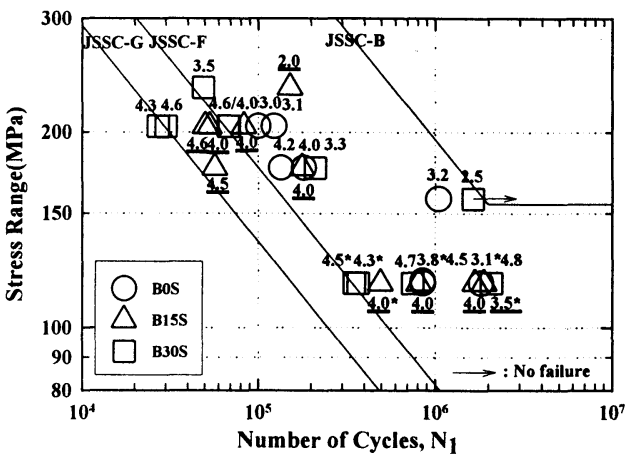

Fig.13 All test results of B0S, B15S and B30S specimens

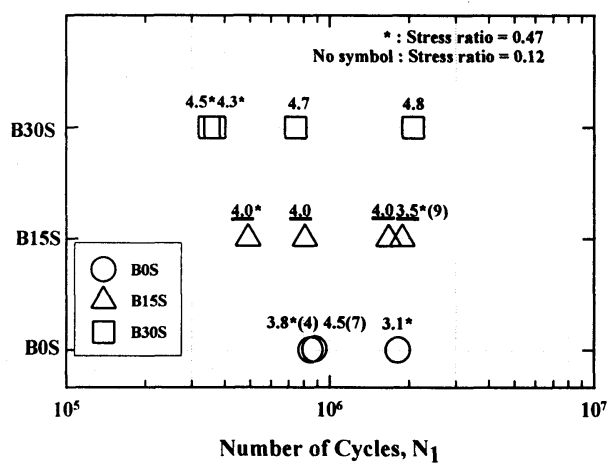

Fig.14 Test results for $117 \mathrm{MPa}$ stress range

were measured using enlarged photograph of the fracture surfaces after the fatigue tests. They are expressed by $H$ and $W$ as listed in the Table A1, where $2 \mathrm{H}$ and $2 \mathrm{~W}$ represent the depth and the length of a rectangular which encloses the $\mathrm{LOP}^{7), 8}$ as shown in Fig.10. The test results are plotted in S-N diagrams, as shown in Figs.12 to 16. The ordinate of the figures represents the nominal stress ranges based on the section A-A in Fig.11. For the test results of B0G specimens with the weld reinforcements, the stress ranges based on the section B-B in Fig.11 are taken additionally. In calculating the stress range, the area of the LOP is not considered.

The numbers written above or below symbols in the S-N diagrams indicate the LOP-depth, $2 \mathrm{H}$, and the specimen-numbers are written in the parentheses. The numbers representing the LOP-depth in B15S specimens are underlined. When the specimens are tested with the stress ratio of 0.47 , they are specified with symbol *.

\section{(2) B0G specimens}

The test results of B0G specimens are plotted in Fig.12 with the nominal stress ranges with symbol $\diamond$. Two B0G specimens, which exhibited fatigue cracks from the ground weld toes, seem to exhibit fatigue lives comparable to JSSC-C ${ }^{7}$. The other two specimens, which did not show any fatigue cracks from the ground weld toes, exhibit fatigue lives even longer than JSSC-C.

The test results are replotted with symbol $\nabla$ for the stress ranges computed using the section area considering the weld reinforcements, the section B-B in Fig.11. All the data are plotted with arrows, because no fatigue failure caused by fatigue crack initiation from the LOP at the number of cycles was observed for B0G specimens. However, all these specimens exhibited small cracks of 0.7 to $1.1 \mathrm{~mm}$ at the edge of the LOP. If we continued the fatigue tests, it was possible that these fatigue cracks propagated to the final failure.

From the comparison of test results of B0G and B0S specimens plotted with the nominal stress ranges, it is understandable that the weld reinforcements reduced the stress range at the LOP, and therefore the fatigue lives of B0G specimens were longer than those of BOS specimens.

\section{(3) B0S, B15S and B30S specimens}

\section{a) All the test results}

All the test results of B0S, B15S and B30S specimens without weld reinforcements are plotted by the nominal stress range versus number of cycles $\mathrm{N}_{1}$, as shown in Fig.13. All the test results except five data show longer fatigue life than JSSC-F and the five test results are distributed between JSSC-G and $\mathrm{F}$. The fatigue life of the test results tends to depend on the LOP-depth. The longer the LOP-depth is, the shorter the fatigue life results.

\section{b) Test results for $117 \mathrm{MPa}$ stress range}

As shown in Fig.13, test results are scattered, even though the LOP-depth is about the same. Especially, the test results obtained from $117 \mathrm{MPa}$ stress range are widely scattered, as shown in Fig.14. The ordinate of the figure is conveniently taken as 
the names of the test specimens.

For B0S specimens, the fatigue life of B0S-7 specimen with the stress ratio, $R$, of 0.12 is equal to that of B0S-4 specimen, even though the LOP-depth is longer. In case of B15S and B30S specimens, the mean fatigue life of the test results obtained for $\mathrm{R}=0.12$ shows twice longer than that of the test results for $\mathrm{R}=0.47$, even though the LOP-depth is about the same or longer. The comparison of the fatigue lives shows that the fatigue lives for $\mathrm{R}=0.12$ tend to be longer than those for $\mathrm{R}=0.47$, even though the LOP-depths for $\mathrm{R}=0.12$ are equal or longer than those for $\mathrm{R}=0.47$. This can be explained by assuming existence of compressive residual stress around the LOP-edge ${ }^{13)}$. If the compressive residual stress existed near the LOP-edge, it brought the minimum stress of $16.3 \mathrm{MPa}$ for $\mathrm{R}=0.12$ in compression, and thus reduced the stress ranges in tension. This yielded normally in longer fatigue life. On the contrary, when the specimens were tested in higher minimum stress of $103.8 \mathrm{MPa}$ for $\mathrm{R}=0.47$, compressive residual stress was not large enough to bring the minimum stress in compression. We estimated the compressive residual stress as about 40MPa from the comparison of the test results. In this respect, the test results obtained for $117 \mathrm{MPa}$ stress range and $\mathrm{R}=0.12$ are excluded in the following discussion in order that the LOP-depth is taken as the basis to examine the effect of inclined angles on the fatigue life. The test result of B15S-9 specimen is also excluded because of its different fatigue crack propagation pattern, as shown in Fig.7(b).

\section{c) Test results for $\mathbf{2 . 0}$ to $3.5 \mathrm{~mm}$}

The test results of $\mathrm{B} 0 \mathrm{~S}, \mathrm{~B} 15 \mathrm{~S}$ and $\mathrm{B} 30 \mathrm{~S}$ specimens with the LOP-depth of 2.0 to $3.5 \mathrm{~mm}$ are plotted in Fig.15. The solid line in the figure represents the mean $\mathrm{S}-\mathrm{N}$ curve obtained from the test results of four B0S specimens with LOP-depth of 3.0 to $3.2 \mathrm{~mm}$. From comparison of the $\mathrm{S}-\mathrm{N}$ curve and two test results of B30S specimens with the LOP-depth of 3.3 and $3.5 \mathrm{~mm}$, it can be assumed that the fatigue lives of B0S and B30S specimens are almost the same. Two test results, B15S specimen with the LOP-depth of $2.0 \mathrm{~mm}$ and B30S specimen with the LOP-depth of $2.5 \mathrm{~mm}$, have shorter LOP-depth than B0S specimens, and therefore fatigue lives of them are longer than those of B0S specimens.

\section{d) Test results for 3.8 to $4.6 \mathrm{~mm}$}

The test results of $\mathrm{B} 0 \mathrm{~S}, \mathrm{~B} 15 \mathrm{~S}$ and $\mathrm{B} 30 \mathrm{~S}$ specimens with LOP-depth of 3.8 to $4.6 \mathrm{~mm}$ are plotted in Fig.16. The solid line represents the mean S-N curves of B0S with the LOP-depth of 3.8 to $4.2 \mathrm{~mm}$. Among four B15S specimens with the

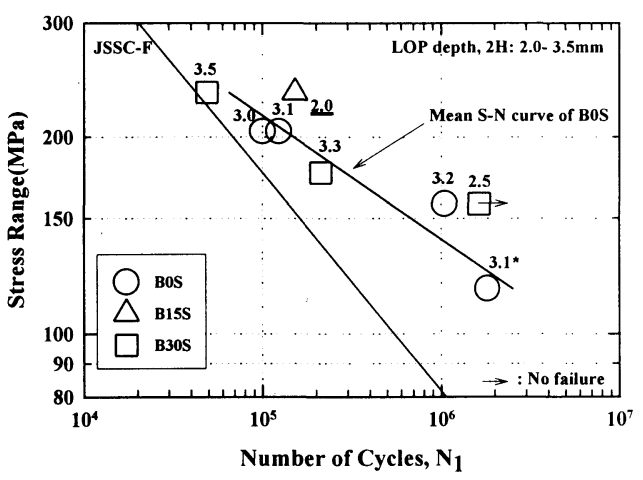

Fig.15 Test results for LOP-depth of 2.0 to $3.5 \mathrm{~mm}$

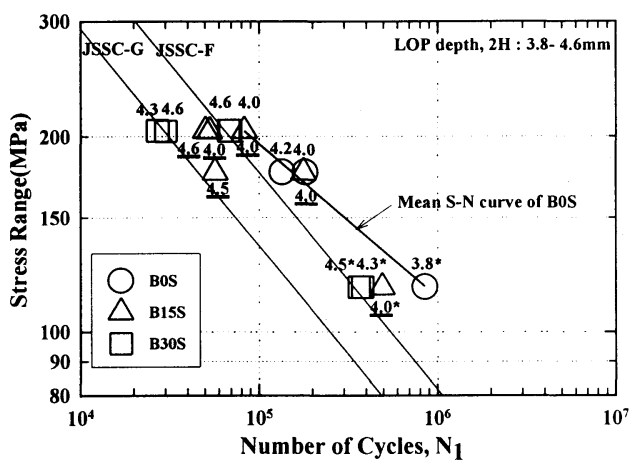

Fig.16 Test results for LOP-depth of 3.5 to $4.6 \mathrm{~mm}$

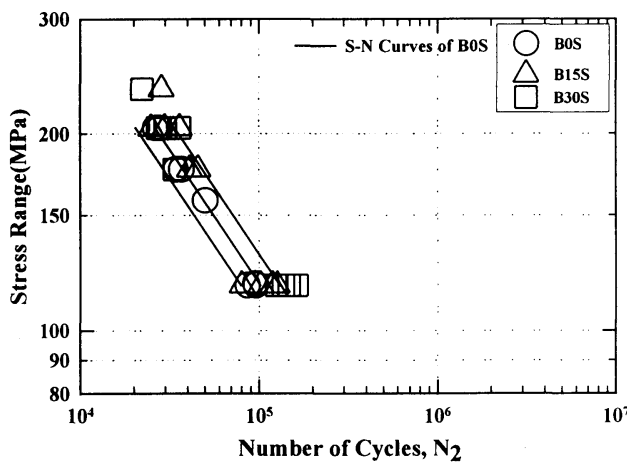

Fig.17 Test results rearranged by number of cycles, $\mathrm{N}_{2}$

LOP-depth of $4.0 \mathrm{~mm}$, two data show the same and the other two data show shorter fatigue life than the mean S-N curve of B0S. The fatigue life of most test results tends to depend on the LOP-depth irrespective of the inclined angles. The longer the LOP-depth is, the shorter the fatigue life is.

\section{(4) Test Results plotted by $\mathbf{N}_{2}$}

Fig. 17 shows test results plotted by $\mathrm{N}_{2}$, number of cycles needed to propagate the crack from the through-thickness crack to cut the wire glued at $50 \mathrm{~mm}$ away from the sides of the specimens. The solid lines represent the mean and mean $\pm 2 \mathrm{~s} \mathrm{~S}-\mathrm{N}$ 
curves (s: standard deviation) obtained from the test results of all B0S specimens. The test results of B15S and $\mathrm{B} 30 \mathrm{~S}$ specimens are mainly distributed between the mean $\pm 2 \mathrm{~s}$ S-N curves, despite the inclined angles. This implies that the effect of the inclined angles of 0 to 30 degrees on the fatigue life of a plate with a through-thickness crack of about 30 to $36 \mathrm{~mm}$ long is little.

\section{(5) Discussion}

In the present test, the LOP-depth is about one-tenth of the LOP-length and no fatigue crack propagation in the width direction was observed. The effect of the inclined angles on fatigue life was examined using the LOP-depth. The test results were divided into two groups according to the LOP-depth of 2.0 to $3.5 \mathrm{~mm}$ and 3.8 to $4.6 \mathrm{~mm}$. In this way, fatigue life for almost equal LOP-depth and different inclined angles can be compared.

When a crack or crack-like-defect is placed with certain angles to the applied stress, it may be expected that the fatigue life increase according to the increase of the inclined angle because the normal stress to the crack-plane decreases. However, test results show that the fatigue lives of B0S, B15S and B30S specimens are almost the same, when the LOP-depth is about the same.

\section{SUMMARY OF FINDINGS}

In order to study fatigue behavior of welded joints including weld defects with certain angles to the applied stress, butt welded specimens containing lack-of-penetration(LOP) with 2.1 to $4.8 \mathrm{~mm}$ deep and 30 to $36 \mathrm{~mm}$ long rectangular shape were fatigue-tested. The inclined angles were 0,15 and 30 degrees from the perpendicular direction to uni-axial tensile cyclic loading. From the test results, the following findings are obtained.

1) Fatigue cracks were simultaneously initiated along the edge of the LOP and propagated toward the thickness direction in the same plane as the LOP inclined to the applied stress. After the crack appeared at the surfaces of the specimen, the through-thickness crack tended to propagate perpendicularly to the applied stress.

2) The LOPs significantly reduce the fatigue lives of $9 \mathrm{~mm}$ thick transverse butt welded specimens with the weld reinforcements removed. All the test results show shorter fatigue life than JSSC-B which basically derived from the specimens with no detectable weld defects.
3) Little change in the fatigue life, number of cycles needed to propagate the crack from the edge of the LOP to the surfaces of the specimen, was observed despite the inclined angles of 0,15 and 30 degrees. 4) The effect of the inclined angles on the fatigue life of a plate with a through-thickness crack of about 30 to $36 \mathrm{~mm}$ length is little.

ACKNOWLEDGMENT: The authors are grateful to Dr. Yoshinaga SAKAI of the TOPY Industries, Ltd. for manufacturing the test specimens.

\section{APPENDIX SUMMARY OF TEST DATA}

Table A1 Summary of fatigue test results (a) B0G specimens ( $\alpha=0$ deg.)

\begin{tabular}{|c|c|c|c|c|r|c|}
\hline No & $\begin{array}{c}\Delta \sigma \\
(\mathrm{MPa})\end{array}$ & $\begin{array}{c}\Delta \sigma_{\mathrm{BB}} \\
(\mathrm{MPa})\end{array}$ & $\begin{array}{c}\text { LOP } \\
\text { Depth } \\
(\mathrm{mm})\end{array}$ & $\begin{array}{c}\text { Crack } \\
\text { from LOP } \\
(\mathrm{mm})\end{array}$ & $\begin{array}{c}\mathrm{N}_{1} \\
\left(\times 10^{3}\right)\end{array}$ & Failure \\
\hline 1 & 204.3 & 115.0 & 3.0 & 1.0 & 531 & Toe \\
\hline 2 & 204.3 & 115.0 & 2.5 & $0.1 \sim 1.1$ & 426 & Toe \\
\hline 3 & 158.0 & 98.8 & 2.5 & $\sim 1.1$ & $>1,596$ & - \\
\hline 4 & 158.0 & 88.9 & 3.2 & $\sim 0.8$ & $>2,289$ & - \\
\hline
\end{tabular}

$\Delta \sigma:$ Nominal stress range, LOP : Lack-of-penetration $\Delta \sigma_{\mathrm{BB}}$ : Stress range considering weld reinforcements

$\mathrm{R}$ : Stress ratio $\left(\sigma_{\min } / \sigma_{\max }\right), \quad>$ : No failure

(b) B0S specimens ( $\alpha=0$ deg.)

\begin{tabular}{|c|c|c|c|r|r|c|}
\hline \multirow{2}{*}{ No. } & $\begin{array}{c}\Delta \sigma \\
(\mathrm{MPa})\end{array}$ & $\mathrm{R}$ & \multicolumn{2}{|c|}{ LOP Size $(\mathrm{mm})$} & \multirow{2}{*}{$\mathrm{N}_{1}$} & $\mathrm{~N}_{2}$ \\
\cline { 4 - 6 } & & $2 \mathrm{~W}$ & $2 \mathrm{H}$ & $\left(\times 10^{3}\right)$ & $\left(\times 10^{3}\right)$ \\
\hline 1 & 204.3 & 0.07 & 31.4 & 3.0 & 100 & 28 \\
\hline 2 & 158.0 & 0.09 & 31.2 & 3.2 & 1,047 & 50 \\
\hline 3 & 176.3 & 0.08 & 36.0 & 4.0 & 182 & 37 \\
\hline $4^{*}$ & 117.2 & 0.47 & 33.6 & 3.8 & 850 & 95 \\
\hline 5 & 204.3 & 0.07 & 34.8 & 3.1 & 123 & 26 \\
\hline 6 & 176.3 & 0.08 & 34.1 & 4.2 & 135 & 34 \\
\hline 7 & 117.2 & 0.12 & 35.0 & 4.5 & 853 & 86 \\
\hline $8^{*}$ & 117.2 & 0.47 & 31.2 & 3.1 & 1,814 & 96 \\
\hline
\end{tabular}

(c) B15S specimens $(\alpha=15$ deg.)

\begin{tabular}{|c|c|c|c|c|r|r|}
\hline \multirow{2}{*}{ No. } & $\begin{array}{c}\Delta \sigma \\
(\mathrm{MPa})\end{array}$ & $\mathrm{R}$ & \multicolumn{2}{|c|}{ LOP Size $(\mathrm{mm})$} & $\mathrm{N}_{1}$ & \multirow{2}{*}{$\mathrm{N}_{2}$} \\
\cline { 4 - 5 } & & $2 \mathrm{~W}$ & $2 \mathrm{H}$ & $\left(\times 10^{3}\right)$ & $\left(\times 10^{3}\right)$ \\
\hline 1 & 234.4 & 0.07 & 31.0 & 2.0 & 152 & 28 \\
\hline 2 & 176.3 & 0.08 & 31.5 & 4.0 & 177 & 45 \\
\hline 3 & 204.3 & 0.07 & 31.7 & 4.0 & 83 & 29 \\
\hline 4 & 204.3 & 0.07 & 33.9 & 4.6 & 50 & 36 \\
\hline 5 & 117.2 & 0.12 & 35.2 & 4.0 & 807 & 101 \\
\hline 6 & 117.2 & 0.12 & 35.0 & 4.0 & 1,673 & 126 \\
\hline 7 & 204.3 & 0.07 & 31.5 & 4.0 & 53 & 25 \\
\hline $8^{*}$ & 117.2 & 0.47 & 32.2 & 4.0 & 492 & 119 \\
\hline $9 *$ & 117.2 & 0.47 & 32.0 & 3.5 & 1,884 & 80 \\
\hline 10 & 176.3 & 0.08 & 33.7 & 4.5 & 57 & 41 \\
\hline
\end{tabular}


(d) B30S specimens( $\alpha=30$ deg.)

\begin{tabular}{|c|c|c|c|c|r|r|}
\hline \multirow{2}{*}{ No. } & $\begin{array}{c}\Delta \sigma \\
(\mathrm{MPa})\end{array}$ & $\mathrm{R}$ & \multicolumn{2}{|c|}{ LOP Size $(\mathrm{mm})$} & $\mathrm{N}_{1}$ & $\mathrm{~N}_{2}$ \\
\cline { 4 - 6 } & & & $2 \mathrm{~W}$ & $2 \mathrm{H}$ & & \\
\hline 1 & 234.4 & 0.07 & 31.2 & 3.5 & 48 & 22 \\
\hline 2 & 158.0 & 0.09 & 29.6 & 2.5 & $>1,634$ & - \\
\hline 3 & 204.3 & 0.07 & 36.0 & 4.0 & 68 & 27 \\
\hline 4 & 204.3 & 0.07 & 33.5 & 4.5 & 67 & 36 \\
\hline 5 & 176.3 & 0.08 & 32.5 & 3.3 & 211 & 33 \\
\hline 6 & 117.2 & 0.12 & 32.7 & 4.8 & 2,069 & 146 \\
\hline 7 & 117.2 & 0.12 & 33.7 & 4.7 & 745 & 162 \\
\hline 8 & 204.3 & 0.07 & 32.5 & 4.6 & 30 & 30 \\
\hline 9 & 204.3 & 0.07 & 32.0 & 4.3 & 27 & 28 \\
\hline $10^{*}$ & 117.2 & 0.47 & 31.2 & 4.3 & 367 & 124 \\
\hline $11^{*}$ & 117.2 & 0.47 & 31.6 & 4.5 & 363 & 136 \\
\hline
\end{tabular}

\section{REFERENCES}

1) Fahimuddin, F., Miki, C., Kanai, T., Anami, K. and Machida, F.: Flaw Assessment of Butt-welded Joints, Proc. of EASEC 7, Vol.1, pp. 231-236, 1999.

2) Newmann, R.P. and Dawes, M.G.: Exploratory Fatigue Tests on Transverse Butt Welds Containing Lack of Penetration, British Welding Journal, pp. 117-120, 1965.

3) Gill, S.J., Hauser, J.A., Crooker, T.W., Kruse, B.J., Menon, R. and Lundin, C.R.: Fatigue Behavior of $5 \mathrm{Ni}-\mathrm{Cr}-\mathrm{Mo}-\mathrm{V}$ Steel Weldments Containing Fabrication Discontinuities, ASTM STP945, pp. 1025-1049, 1988.

4) Harrison, J.D.: The analysis of fatigue test results for butt welds with lack of penetration defects using a fracture mechanics approach, Inst. Weld Non-destructive Testing Conf., London, pp. 777-789, 1967.

5) Ishii, Y. and Iida, K.: Low and Intermediate Cycle Fatigue Strength of Butt Welds Containing Weld Defects, Journal of N.D.I(Japan), Vol. 18, No. 10, pp.443-475, 1969.

6) Shah, R.C.: Fracture Under Combined Modes in 4340 Steel, Fracture Analysis, ASTM STP 560, American Society for Testing and Materials, pp. 29-52, 1974.

7) JSSC: Fatigue Design Recommendations for Steel Structures, 1995.

8) International Institute of Welding: Recommendation on Fatigue of Welded Components, IIW Document XIII-1539-96/XV-845-96, 1996.

9) Mori, T. and Tokida, H.: Fatigue Crack Initiation and Propagation from Angled Weld Cracks, Structural Eng./Earthquake. Eng. Vol. 6, No. 2, pp. 319s-326s, 1989.

10) Erdogan, F. and Sih, G.C.: On the Crack Extension in Plates Under Plane Loading and Transverse Shear, Journal of Basic Engineering, pp. 519-527, 1963.

11) Otsuka, A., Tohgo, K. and Yoshida, M.: Fatigue Crack Growth of a Mixed Mode Three-Dimensional Crack, JSME(series-A), Vol. 54, No. 505, pp. 1735-1744, 1988.

12) Yoshioka, S., Watanabe, K. Kitagawa, H., Inoue, A. and Kumasawa, M.: Fatigue Crack Growth Threshold( $\Delta \mathrm{Kth})$ under Mode III(The Effect of Stress Ratio and Mixed Mode), JSME(series-A), Vol. 50, No. 454, pp. 1267-1274, 1984.

13) Yamada, K., Kainuma, S., Suzuki, M. and Kondo, A.: Fatigue of In-plane Gusset with Static Load in Main Plate, Journal of Structural Engineering, JSCE, Vol. 44A, pp. 1073-1082, 1998.

\section{斜めに未溶着部を有する突合せ溶接継手の疲労挙動}

\section{金仁泰・山田健太郎・貝沼重信}

作用応力に対して斜めに溶接欠陥を有する溶接継手の疲労挙動を検討するために, 作用応力の直角方向 に対して $0,15,30$ 度傾いた未溶着部を有する突合せ溶接継手の引張疲労試験を行なった. 疲労き裂は未溶着 部之同一面で板厚方向に進展し, 板厚貫通後, 作用応力に対して直角に進展した. また, 未溶着部が $0,15,30$ 度傾いても，ほとんど疲労寿命は変化しなかった。 